\title{
Medical ethics and medical practice: a social science view
}

\author{
Margaret Stacey Department of Sociology, University of Warwick, Coventry
}

\section{Author's abstract}

This paper argues that two characteristics of social life impinge importantly upon medical attempts to maintain high ethical standards. The first is the tension between the role of ethics in protecting the patient and maintaining the solidarity of the profession. The second derives from the observation that the foundations of contemporary medical ethics were laid at a time of one-to-one doctor-patient relations while nowadays most doctors work in or are associated with large-scale organisations. Records cease to be the property of individual doctors, become available not only to other doctors but also to educational and social work personnel. Making records openly available to patients is suggested as the only antidote to this irreversible loss of individual practitioner control. The importance for doctors of understanding the nature of professional and bureaucratic organisations in order to deal with the hazards involved is stressed as is the responsibility of the General Medical Council to regulate medical competence as well as personal behaviour.

How might a social science view of medical ethics and medical practice be different from any other? First, a social scientist is interested in the nature of the social relations in which and to which ethical principles are to be applied and what power relations are involved. Second, social science assumes that medical knowledge and medical practice are not neutral but are social institutions essentially similar to other social institutions. They arise, change and adapt in historic time and in response to social, economic and technical change $(1,2,3,4,5,6,7)$.

Medicine as a social institution has rather distinct features however: first, its central intention of alleviating human suffering; second, the control over life and death which may be in its practitioners' hands. These two features are connected, for this power over another derives from a circumstance in which that other is seeking relief from suffering. Many of the ethical dilemmas derive from this conjunction and

\section{Key words}

Ethics; doctor-patient relations; large-scale organisations; professional solidarity; public responsibility; patient records; confidentiality; medical competence. from the social relations which ensue.

Medicine is one of a larger class of human service work or 'people work' in which one person or group of people seek to manipulate the minds or bodies of others (education and social work are other examples). As Everett Hughes, that wise American sociologist, said:

'In many of the things which people do for one another, the for can be changed to to by a slight overdoing or shift of mood' (8).

He was pointing to the way in which a situation of service can become one of domination or disservice because of the nature of the work being done and of the social relations involved. $\mathrm{He}$ was not speaking of situations where there is an initial intention to abuse skill or exploit the patient, but of the hazards of everyday practice.

As well as in the detailed social psychology and sociology of everyday life in the hospital ward or clinic, large social structures of themselves give rise to ethical problems: the hospital and the organisation of the medical profession itself are prime examples.

To take professional organisation first: social scientists have observed that while codes of ethics appear to exist to protect the client, in practice they have a very great deal more to do with the protection of the profession, see, for example, (9). This is true of all professions. For example, the Hippocratic Oath, as Jacob (10) has recently reminded us, has two facets relating to the duty of confidence. The first is the undertaking to the patient:

'And whatever I see or hear when attending the sick, or even apart therefrom, which ought not to be told, I will never divulge but hold as a secret.'

The second relates to confidence among professionals:

'I will teach . . . to my sons [sic], the sons of my teacher and to pupils who have sworn the Oath of a Physician, but to no one else.'

As Cartwright (11) the medical historian has argued:

'The essence of the Oath is a promise to support 
members of the group, to confine teaching of the art to a closed circle, and not to reveal the mysteries to anyone outside that circle. It embodies a high ethical standard ... Thus the Hippocratic Oath ensured a "closed shop" and this closed shop persists today in the differentiation between the privileged registered practitioner and the unregistered quack'. Quoted by Jacob, (10).

This 'closed shop' sharply differentiates not only the registered practitioner from the quack but also the registered practitioner from the lay client.

Seidler (12) reminds us that in Germany:

'In the 19th century, professional ethics began to reveal distinctive features which emerged as a result of certain social and class-political controversies. Owing to changes which took place in the middle of the century within the professional and ethical structures of medicine, physicians were obliged on the one hand to defend their social position and professional line of conduct towards other people and, on the other, to attempt stabilisation within their own class. The appearance of highly differentiated and rather rigid rules concerning the so-called "dignity of the profession" resulted from this attitude. These rules referred in particular to loyalty to one's colleagues, obligations towards the law and the maintenance of professional autonomy. For this reason, it is in this rather special sense that the term "medial ethics" is still often used and understood.'

Although the detail of British history differs from the German experience quoted here, as does the history of the relations between the profession of medicine and the State in the two countries, nevertheless a similar account of medical ethics could be written for Britain. This in-group solidarity and its associated ethics, while always carefully guarded, may be most stressed in times of medical insecurity whether the threat is to an individual or the profession as a whole.

The 1894 definition of 'infamous conduct in a professional respect' by Lord Justice Lopes is reprinted in the General Medical Council's blue book Professional Conduct and Discipline: Fitness to Practice:

'If a medical man [sic] in the pursuit of his profession has done something with regard to it which will be reasonably regarded as disgraceful or dishonourable by his professional brethren of good repute and competency, then it is open to the General Medical Council, if that be shown, to show that he has been guilty of infamous conduct in a professional respect' (13).

In 1930 Lord Justice Scrutton ruled that serious misconduct and infamous conduct were the same and that is how the council sees it today. The question is how does the council define such conduct. The following gives an indication: (i) Neglect or disregard by doctors of their professional responsibilities to patients for their care and treatment.

(ii) Abuse of professional privileges or skills.

(iii) Personal behaviour: conduct derogatory to the reputation of the medical profession.

(iv) Advertising, canvassing and related professional offences (14).

The first two of these clearly relate to duties towards patients: the second two to the 'dignity of the profession' and its solidarity. An analysis of cases brought and their outcome would be needed to show which in practice of these two tendencies, defence of the profession or defence of the patient, comes uppermost in the self-regulatory procedures of the profession.

I do not wish to imply that professional solidarity necessarily works against the public interest. There are some hints that in countries where the profession is well regulated in terms of the 'dignity of the profession' its standards of conduct in respect of duty to the patient are also higher. To my knowledge we lack good empirical evidence for that proposition. But one cannot assume that the well regulated medical closed shop necessarily works in the best interests of patient and public. In any case a balancing act between responsibilities to the public and to the profession has to be done to retain the solidarity of the profession at the same time as raising standards and responding to changing patient circumstances and demands.

Modern medicine sets these long-established dilemmas in a different context from that of the 19th century. The problems are posed by the large-scale social organisations in which and with which many doctors have to work. How to guarantee confidentiality when so many different kinds of staff see and handle records is difficult of itself. Some clear understanding of the ways in which bureaucracies work is needed. Many others may be consulted about a case and involved with tests and assessments. Other large-scale organisations beside health service ones are also involved, educational and social services for example. The awareness of doctors of the ethical implications are essential here.

In a paper in 1982 Dr Pheby pointed out that authority is ascribed to medical opinions not only because of the esteem in which the medical profession is held but also because medical opinions are generally considered to be scientific. Yet, he argues, many medical judgements contain value judgements which are not scientific since they cannot be falsified. Once having passed into the files however they become inaccessible and incapable of correction. They may have the effect of 'labelling' the patient in such a way that the subsequent judgement of that doctor or of others is clouded or warped. He cites three cases I had earlier reported of mothers who were tranquillised as 'anxious' when their anxieties were ultimately shown to be justified upon a diagnosis in their children of

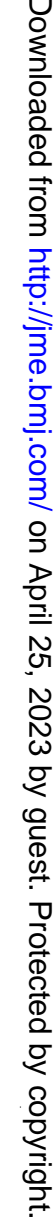


congenital dislocation of the hip. In these cases the doctor had failed to perceive a physical disability in the child, thinking the problem was in the mother's mind. They were apparently not cases in which the mother was tranquillised in the belief that this would help her deal with a serious and well-founded anxiety. Pheby argues that in those cases:

'There were in fact two hypotheses, one non-scientific ("this mother is anxious") and one scientific ("this child is not ill"). The latter "scientific" hypothesis, being a null hypothesis, could be falsified by a positive finding, and this is clearly what happened eventually, rendering the "non-scientific" hypothesis irrelevant' (15).

Or perhaps not so much that as demonstrating that the mothers' anxieties were not imaginary or pathological but well-founded: those mothers' observations of their children were in advance of their physicians'. The attribution of 'anxious mother' which assumed neurosis, or similar pathology, was based on nothing more than the repeated presentation of a child the mothers felt to be ill and who was later shown to be ill. The ability of mothers to recognise serious illness in a child, even if they are unable to name the trouble, has been demonstrated by Spencer (16). Clearly Dr Pheby has performed an important service in drawing our attention to the hazards of such data being on file, particularly as it may be used by others in a different context. Dr Pheby bases his argument on a distinction between hard and soft data.

Yet I am not convinced that this distinction which is also being suggested by the European Economic Community Conseil des Ordres can be sustained as clearly as Dr Pheby thinks. In an article with clearly humane intentions Dr Robertson (17) discusses ways of preserving the dignity of brain-damaged elderly people. He appears to have no doubt that he is dealing with a diagnosable organic condition for which positive evidence can be presented. Yet he makes no mention of psycho-social circumstances which may lead to similar symptoms. He discusses various options, focusing on one he calls 'dignity not senility for the elderly' and discusses circumstances in which it might be best not to initiate treatment. He continues:

'Patients who subject themselves to serious indignities such as persistent shouting or screaming represent a group who merit more rational, and at the same time more compassionate, management, even if the necessary sedative treatment promotes the development of a life-threatening condition' (18).

The assumption of individual responsibility in the phrase 'subject themselves' I find interesting. We are all aware of the phenomenon of the elderly confused, the apparent departure from the living body of the person we knew and associated tiresome behaviour, wandering, babbling, inexplicable aggression and the like. At the same time are we quite clear how we might distinguish between organic brain damage and those whose 'awkward' or 'bad' behaviour may derive from the indignities they are presently experiencing in a hard-pressed geriatric ward? How much do we really know about the social and psychological circumstances which can send an elderly patient 'demented'?

Another area in which a good deal of conceptual confusion occurs is the paediatric assessment of handicap. It is quite common for paediatricians and others to record ' $\mathrm{ESN}(\mathrm{S})$ ' - (severely educationally subnormal) as a diagnosis of a child. What this appears to mean is that as a consequence of multidisciplinary assessment and sometimes in anticipation of it, the paediatrician concludes that the child has special educational needs. As my colleague Dyson has argued (in an unpublished comment on Family Focus 1983, a Coventry-based group of parents), drawing on Tomlinson (19) needs are not a diagnosis nor is ESN a medical category.

Many ethical problems surround multi-disciplinary work. And always many people are involved in one person's treatment. Doctors may cloud the vision of others involved in a case by unsubstantiated comments of a stereotyping kind. How much more important is this when the diagnosis will be picked up and acted upon by other authorities, say education or social services.

Many files contain an implicit evaluation of parents by professionals, an evaluation seemingly based on the degree to which parents react to circumstances in the way professionals think appropriate, and on the extent to which these reactions help or hinder professional work. These judgements may later influence decisions about the child or members of the family at some crucial stage in their future lives. How careful therefore doctors have to be that only well substantiated and publicly defensible comments are recorded!

Cohen (20) reports that in a hospital where an open records system has been established doctors talk through their 'contentious' comments with patients before making or recording them. Throwaway remarks are no longer put down unthinkingly remarks of the kind that can take on the appearance of fact after a time.

The 'closed system' in which the medical profession works, wherein the greater part of social as well as professional time is spent with other professionals, leads to the development of norms about what it is acceptable to say and do about patients which would not be acceptable in more mixed company. It is in a similar sheltered context that ill-advised comments may be made in records. Where what is on record is purely technical organic information this may not be dangerous. Where, as may be the case, social or personal judgements are also involved such norms may reflect a particular class position, particular sets of privileged social experiences not shared by the rest of the population. A solution may be more openness. Practitioners may fear that making available their 
judgements might destroy trust. On the contrary one can argue that the patient-held or parent-held record and open patient access to records may help to create that trust which is necessary between professional and client if co-operation in treatment is to be achieved. Undoubtedly ethical ends are likely to be better served by openness.

With regard to the doctor/patient relationship, Dr David Hall (in a paper on the ethics of medical research read to the 1983 Medical Sociology Conference) has pointed out that those ethical principles which suggest to doctors that they should withhold information from patients 'in the patients' best interest' seem to derive from a model of the relationship where the doctor is seen as active and the patient passive, as opposed to a partnership in healing or managing disease which requires that the patient be active in decision-making. All our evidence to date suggests that generally speaking doctors dominate the consultation process and also other health care professionals $(21,22$, $23,24,25$ but see also 26). The argument for an equal partnership on ethical grounds is therefore a radical one but derives from an analysis of evidence. Such little evidence as we have suggests that most doctors, including those who say they treat individual cases on their merits do in practice follow a routine which varies little from patient to patient, or varies on a stereotypical basis (27).

To conclude. I have argued that education is required to draw attention to the way in which the social organisation of the medical profession may lead doctors to emphasise those facets of medical ethics which relate to the protection of the profession rather than to those designed to protect the public. Also I have argued that an understanding of the complex social organisation of medical practice is necessary to alert practitioners to the ethical implications of their actions. Two facets are particularly important: first, the nature of the social distance between doctor and patient and the relative powerlessness of the latter which leads to an ever present hazard that she/he will be unconsciously treated as an object, not a full and equal human being. The hypothesis that this hazard would be reduced if records were open to patients merits systematic study. Second, the social nature of the large-scale organisation of hospital medicine and of welfare and educational authorities requires systematic study. I have shown how records circulating round a number of authorities can render a doctor almost powerless to retrieve mistaken judgements once they have gone on record whether in a manual file or on computer. The rootedness of ethics in social relations requires more systematic understanding than it has hitherto received including an understanding of when secrecy is for the protection of the profession and when for the protection of the public.

What are the implications of these conclusions for the GMC? First, the council must clearly continue to examine its guidelines and procedures carefully to ensure that the weight of its authority is at least as much upon the protection of the public as of the profession. Council has recently discussed the question $\vec{F}$ of the relationship between competence to practice and $\bar{\delta}$ professional conduct. It has agreed to point out to $\Rightarrow$ doctors that they have privilege in raising with council $\stackrel{\vec{P}}{+}$ fears about a colleague's malpractice or incompetence? in practice. This is well because what Stebbing (28) said many years ago remains true:

'If the doctor is to do his work he must be trusted. $\stackrel{\triangle}{\circ}$ This does not mean merely that the doctor must be kindly and personally reliable and punctilious in $\vec{\circ}$ performing his engagements; he must be reliable in his medical knowledge and skill; ...' (Emphasis in $\vec{\omega}$ original).

Council might wish to continue to work to reduce the large grey area in which doctors are not prepared to comment on each others' actions in practice. Such a $\overrightarrow{\vec{\Delta}}$ reduction would be in the interests of the profession $\vec{A}$

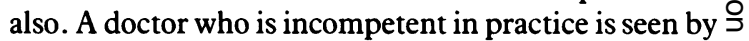
the public quite simply as 'doing wrong'. Lay people $\vec{\longrightarrow}$ have no difficulty in seeing this as an ethical issue. All doctors are aware how difficult such judgements are. More openness as to records would help the public to share these problems too.

\section{Acknowledgements}

Simon Dyson's contribution to this paper was particularly appreciated.

\section{References}

(1) Abel-Smith B. Value for money in health services London: Heinemann, 1976.

(2) Armstrong D. Political anatomy of the body. Cambridge: Cambridge University Press, 1983.

(3) Foucault M. The birth of the clinic: an archaeology of medical perception. London: Tavistock, 1973.

(4) Jewson N D. Medical knowledge and the patronage system in 18th century England. Sociology 1974; 8: 369-3 385.

(5) Jewson N D. The disappearance of the sick man from 옥 the medical cosmology. Sociology 1976; 10: 225-244.

(6) Waddington $T$. The role of the hospital in the development of modern medicine. Sociology 1973; $7: \bar{N}$ 211-224.

(7) Wright P, Treacher A, eds. The problem of medical knowledge: examining the social construction of medicine. N Edinburgh: Edinburgh University Press, 1982.

(8) Hughes E. The sociological eye. Chicago: Aldine, $1971: 0$ 305.

(9) Freidson E. Profession of medicine: a study of the sociology of applied knowledge. New York: Dodd Mead, 1972.

(10) Jacob J M. Changing practice on confidentiality: a cause for concern. Commentary 1. Confidentiality: the우 dangers of anything weaker than the medical ethic. $\stackrel{\mathbb{D}}{\mathrm{S}}$ Journal of medical ethics 1982; 8: 18-21.

(11) Cartwright F F. A social history of medicine. London: $\frac{\varrho}{\sigma}$ Longman, 1977.

(12) Seidler E. The teaching of medical ethics in the Federal Republic of Germany. Fournal of medical ethics 1979; 5 :O 76. 
(13) General Medical Council. Professional conduct and discipline: fitness to practise. London: General Medical Council, 1983: 2.

(14) See reference (13): 9.

(15) Pheby D. Changing practice on confidentiality: a cause for concern. Fournal of medical ethics 1982; 8: 12-18.

(16) Spencer N J. The identification and management of illness by parents of young children. M Ph Thesis: University of Nottingham, 1980.

(17) Robertson G S. Dealing with the brain-damaged old dignity before sanctity. Fournal of medical ethics 1982; 8: 173-177.

(18) See reference (17): 175.

(19) Tomlinson S. Educational subnormality: a study in decision making. London, Boston and Henley: Routledge and Kegan Paul, 1981.

(20) Cohen R. Whose file is it anyway? London: National Council for Civil Liberties, 1982.

(21) Freidson E. Professional dominance: the social structure of medical care. New York: Atherton, 1970.

(22) Goldie N. The division of labour among the mental health professions - a negotiated or an imposed order?
In: Stacey M, Reid M, Heath C, Dingwall R. Health and the division of labour. London: Croom Helm, New York, Prodist, 1977: 141-161.

(23) Stimson G, Webb B. Going to see the doctor: the consultation process in general practice. London and Boston: Routledge \& Kegan Paul, 1975.

(24) Illsley R. Professional or public health? Sociology in health and medicine. London: The Nuffield Provincial Hospital Trust, 1980.

(25) Jefferys $\mathbf{M}$, Sachs $\mathbf{H}$. Rethinking general practice: dilemmas in primary medical care. London and New York: Tavistock, 1983.

(26) Armstrong D. The decline of medical hegemony: a review of government reports during the NHS. Social science and medicine. 10: 157-163.

(27) Bloor M. Professional autonomy and client exclusion in ENT out-patient clinics. In: Wadsworth $M$, Robinson $\mathrm{D}$, eds. Studies in everyday medical life. London: Martin Robertson, 1977: 52-68.

(28) Stebbing S. Men and moral principles. London: Humphrey Milford, Oxford University Press, 1944: 2324. 